\title{
O LE MÉTIER DE SOCIOLOGUE É UM CLÁSSICO NA SOCIOLOGIA FRANCESA DA ATUALIDADE?'
}

\section{IS THE CRAFT OF SOCIOLOGY A CLASSIC IN FRENCH SOCIOLOGY NOWDAYS?}

Julien Duval*

Introdução

Que lugar ocupa hoje, cinquenta anos após sua publicação, o Le Métier de sociologue na sociologia francesa? 0 que representa, atualmente, este livro ao mesmo tempo muito presente e um pouco esquecido na cultura dos sociólogos franceses. Desde o início, a questão do lugar do Métier de sociologue pareceu-me muito difícil de tratar, primeiro porque a recepção, a apropriação, e os usos de um livro são sempre difíceis de serem apreendidos; segundo, e de modo mais amplo, porque o papel que desempenha hoje o Le Métier de sociologue não pode ser separado facilmente do papel que desempenha todo o trabalho de Pierre Bourdieu. Assim, minha intervenção ficará presa a essa convicção contraditória segundo a qual o ponto de partida é tão mais interessante quanto maior a dificuldade em tratá-lo. Até o fim, portanto, oscilará entre a tentação de fornecer elementos de resposta específicos ao Métier de socioloque, e de colocar a questão mais ampla sobre a posição que ocupa hoje, na França, Pierre Bourdieu e sua sociologia. Até que ponto a "revolução" que Bourdieu queria empreender na sociologia teve êxito? Evidentemente, nesta "revolução" (o termo merecerá algumas explicações), o Le Métier de socioloque, escrito em co-autoria com Jean-Claude Chamboredon e Jean-Claude

\footnotetext{
* Diretor de pesquisa no Centre National de la Recherche Scientifique - CNRS - (Paris/França). E-mail: jduval@msh-paris.fr

1. Conferência proferida no Colóquio Internacional: 0 ofício de sociólogo e o trabalho sociológico de Pierre Bourdieu. Universidade Federal de Santa Catarina, Florianópois - SC, 17 de maio de 2018. Tradução de Rodrigo da Rosa Bordignon. Revisão de Igor Gastal Grill.
} 
Passeron, não teve o status de "manifesto", mas parece, entre todos os escritos de Bourdieu, aquele mais facilmente comparável às Regras do Método Sociológico - que foi escrito por Durkheim, aliás, com quase a mesma idade. 0 livro exprime a ambição de refundar a sociologia com base em uma epistemologia coerente e reflexiva. Contra as defınições heterônomas, traz a aspiração de que a sociologia seja a matriz de sua própria abordagem. É apenas no segundo momento de minha intervenção, contudo, que tentarei ampliar o foco. A princípio, começarei tentando reunir alguns elementos sobre a "posteridade" do Le Métier de socioloque na sociologia francesa contemporânea.

\section{0 lugar do "Métier de Sociologue"}

Embora Bourdieu tenha assinalado seus limites, a bibliometria pode fornecer algumas indicações gerais. Desde meados dos anos 2000, um portal eletrônico, chamado Cairn, impôs-se na sociologia francófona. Embora não agrupe toda a produção sociológica em língua francesa, reúne um grande número de revistas, notadamente as mais conhecidas e difundidas, além de algumas coleções de livros de pesquisa, de livros didáticos ou de livros de síntese mais voltados para um público estudantil. Neste portal, entre o período 2007-2016, o Le Métier de sociologue teve, em média, 18,2 citações por ano em artigos ou livros. Mesmo que os "clássicos" - como as Regras do Método Sociológico de Émile Durkheim ou as Estruturas Elementares de Parentesco de
Claude Lévi-Strauss - sejam substancialmente mais citados (cerca três vezes mais), o índice de 18,2 não é negligenciável. Ao contrário, sugere que, cinquenta anos após a sua publicação, o Le Métier de sociologue não caiu no esquecimento.

Uma parte de suas citações vem de artigos ou livros que retomam, como tema principal ou secundário, a história da sociologia ou das ciências sociais francesas. A outra evoca regularmente a história da disciplina. Além disso, o livro é constantemente citado em artigos ou livros que se concentram em Bourdieu ou em sua sociologia, sendo geralmente referido como uma das obras importantes que ele (co)escreveu na década de 1960. Mas o interesse conferido ao Métier de sociologue não é apenas de natureza histórica, e pode ser tentador argumentar que o livro é considerado um "clássico" atualmente. Ao lidar com o envelhecimento das obras culturais, Pierre Bourdieu denotou o caso dessas obras "clássicas": são pouco numerosas, e sobrevivem ao autor quando a maioria das outras caem no esquecimento (BOURDIEU, 1992). Sociólogo da instituição escolar, ele gostava de lembrar que o adjetivo "clássico" tem a ver com a palavra “classe”. Um famoso dicionário da língua francesa do século XVII, diz que o adjetivo "clássico" "remete [apenas] aos autores lidos nas salas de aula, nas escolas ou aos que possuem grande autoridade" (FURETIÈRE, 1690).

De fato, a posteridade do Métier de sociologue, livro que nasceu em uma sala de aula ${ }^{2}$, se disputa, principalmente, nas

2. 0 livro é fruto do curso que Bourdieu e Passeron ofereciam (notadamente em 1967, no escopo do "Enseignement pour la recherche approfondie en sciences sociales" - EPRASS -, ofertado pela EHESS e pelo CNRS). Em 1988, Bourdieu explica que eles redigiram o livro para "perpetuar o curso, sem serem obrigados a repeti-lo a cada ano" "Sou um pouco como um velho médico que conhece todas as enfermidades do entendimento sociológico”. Entrevista realizada por Beate Krais - dezembro de 1988 -. Cf. BOURDIEU, CHAMBOREDON, PASSERON, 2005, p. V.). 
"classes" de sociologia. Na ocasião de uma jornada de estudos realizada recentemente em Paris, as comunicações mostram que o livro é utilizado em diferentes instituições e universidades que oferecem o ensino de sociologia ${ }^{3}$. Inclusive, parte das citações de que ele é objeto no portal Cairn são feitas por manuais de formação ou de iniciação à sociologia. Os autores destes manuais não são, necessariamente, antigos alunos de Bourdieu: Le Métier de sociologue não representa atualmente, e de modo efetivo, a expressão de uma "escola sociológica" particular. Alguns autores de manual referem-se a ele por verem, conforme uma das ambições do livro, a formulação de uma "teoria do conhecimento do mundo social" comum às diferentes tradições sociológicas (PERL, 2013); ou por considerarem que a "ruptura com o senso comum", ou mesmo a "construção do objeto", é um imperativo fundamental do trabalho sociológico (PAUGAM, 2015). Em cinquenta anos, nenhum livro desbancou o Le Métier de sociologue no campo da epistemologia da sociologia. A obra, portanto, não está longe de pertencer a uma cultura partilhada, se não pela totalidade dos sociólogos franceses, por uma grande fração da "comunidade".

Se é assim, é porque alguns desejos de Bourdieu, Chamboredon e Passeron foram parcialmente realizados. 0 "métier", no sentido de um habitus, que eles pretendiam transmitir não foi, evidentemente, generalizado, mas a ideia que a sociologia é um ofício que supõem uma competência e um savoir-faire específicos tem, incontestavelmente, progredido nos espíritos e nas estruturas universitárias. As formações especificamente dedicadas à sociologia e à pesquisa sociológica são bem mais numerosas que nos anos 1960. Podemos fazer referência a um livro emblematicamente intitulado "Le métier de sociologue em France depuis 1945". Seu autor, Gérard Houdeville, restitui os resultados de uma longa pesquisa sobre a história recente da disciplina, e conclui que:

a sociologia conseguiu se organizar atualmente, no interior do campo acadêmico francês contemporâneo, como uma autêntica comunidade cientifica. A conquista da autonomia, a existência como um corpo constituído de sociólogos no campo acadêmico aparece como sentido principal que se pode atribuir a esta história dos sessenta últimos anos da sociologia (HOUDEVILLE, 2007, p. 306).

Gérard Houdeville observa que os diversos obstáculos impostos ao desenvolvimento da ciência social enumerados por Bourdieu e Passeron em um texto dos anos $1960^{4}$ foram, hoje, largamente superados.

Em grande medida, poderíamos dizer que a sociologia não é mais esta "disciplina dispersa”, da qual ainda falava Bourdieu nos anos 1980 (BOURDIEU, 2015, p. 460 et seq.). Evidentemente, ela não está unificada em torno de um "paradigma" único ou hegemônico, como é o caso da ciência econômica, e as modalidades de seu recrutamento permanecem bastante diversificadas em comparação às disciplinas nas quais a ocupação de um cargo universitário é implícita ou explicitamente condicionada, na

\footnotetext{
3. Journée d'études “Construction d'objet”, organizada por Louis Pinto, Paris, CNRS-site Pouchet, 27 e 28 de março de 2018.

4. Cf. BOURDIEU, PASSERON (1967).
} 
França, pela posse de uma "agrégation" ${ }^{5}$ " portanto, pela passagem por um mesmo tipo de formação. A sociologia, no entanto, certamente ganhou em homogeneidade. A consciência de fazer parte um grupo que partilha interesses e um savoir-faire específicos progrediu, tal como testemunha o crescente papel das associações profissionais: a ASES 6 , criada em 1989 por sociólogos das profissões desejosos de assegurar “a defesa e a promoção da sociologia no ensino superior"; ou a Association française de sociologie, efetivamente mais ativa que a antiga Société française de sociologie, a qual ela substituiu em 2002. A tendência à homogeneização da disciplina realizou-se, às vezes, em torno de ideias próximas àquelas promovidas pelo Le Métier de sociologue. A convicção que a sociologia é "um oficio", uma prática profissional que se deve proteger contra os “amadores”, esteve, em 2001, no fundamento de uma mobilização de sociólogos, dificilmente imaginável trinta ou quarenta anos mais cedo, destinada a denunciar como "indigna" da profissão uma astróloga midiática que acabara de defender o "doutorado em sociologia”. Podemos pensar, consequentemente, que certos preceitos do Métier de sociologue são atualmente muito mais partilhados entre os sociologos franceses: a "recondução do senso comum”, por exemplo, tem um status de quase falha profissional em muitos dos seminários ou de defesas.

Para retomar uma expressão e uma imagem que Bourdieu utilizava a respeito das revoluções simbólicas bem sucedidas, poderíamos dizer que alguns aspectos do Métier de sociologue tornaram-se o "ar que se respira” na sociologia francesa. A propósito, disso resulta que as ferramentas bibliométricas meçam muito mal a posição do livro. Em parte, o Le Métier de sociologue passou pela "obliteração por incorporação” da qual falava Merton (MERTON, 1965): suas ideias difundiram-se tão bem que ficaram opacas, fazendo-nos esquecer de sua origem. No entanto, evocarei o nome de outro sociólogo que ilustra muito bem este mesmo mecanismo na França: Paul Lazarsfeld. Atualmente, este sociólogo é pouco citado na França, ao passo que sua concepção de sociologia estatística está impregnada em um grande número de ensinamentos “quantitativos”. Podemos dizer, portanto, que o Le Métier de sociologue uniu-se a uma base comum partilhada por inúmeros sociólogos, mas é necessário imediatamente acrescentar - o que complica as coisas - que ele ombreia com muitos de seus principais alvos.

Podemos dizer, talvez, que o Le Métier de sociologue é um "clássico", mas devemos considerar que uma obra que se torna "clássica” também corre o risco de ser parcialmente "neutralizada”. As obras clássicas são obras conhecidas, mas que, justamente por isso, são objeto de um intenso trabalho de vulgarização que pode substituir a leitura direta. Evidentemente, se podemos levantar a hipótese que a maior parte dos sociólogos franceses sabem da existência do Le Métier de sociologue, é bem mais arriscado pensar que são numerosos aqueles que realmente leram o livro. Isso porque, em parte, é possível verificar que as citações feitas do

5. A agrégation é um concurso nacional de acesso aos cargos de professor no ensino secundário (liceu) ou no ensino superior. A aprovação nestes concursos confere o título de agrégé (N. T.).

6. Association des sociologues enseignantes du supérieur. 
livro atualmente são muito superficiais. Por exercício, a invocação deste "clássico" visa, talvez, especialmente exercer um efeito de autoridade quando o livro é reduzido à afırmação da "necessidade de uma atividade fundamentalmente crítica do sociólogo" (BOULET, 2017, p. 23), e o propósito original do livro dissolve-se, porventura, quando o Le Métier de sociologue é citado como um simples apelo à uma epistemologia, atualmente comum, que acumularia "três traços [...]: o empirismo, o verificacionismo e a cumulatividade" (OLLION, 2011, p. 281-282). Nessas condições, podemos compreender que um pesquisador como Louis Pinto, ex-aluno de Bourdieu, convide à releitura do livro: na discussão das jornadas de estudos mencionada acima, ele reivindica que, relativamente à questão da “construção do objeto", centro do Métier de sociologue, há "certa rotinização".

No entanto, e apesar do que foi dito até aqui, alguns elementos sugerem que, ao mesmo tempo, o Le Métier de sociologue é um livro um pouco esquecido. Em todo caso, entre os livros escritos ou co-escritos por Bourdieu, ele não é o mais citato. Considerando o período de 2007 a 2016, com uma media de 18 citações por ano no portal Cairn, ele é mais citado que L'Ontologie politique de Martin Heidegger ou a maior parte dos livros derivados das pesquisas na Argélia, mas é bem menos citado que $L a$ Distinction (81 citações por ano), La Domination masculine (73) ou La Reproduction (70). Além disso, ele está longe de ser o livro de Bourdieu mais acessível fora das bibliotecas universitárias. Está bem menos presente, por exemplo, nas bibliotecas mu- nicipais de Paris do que o La Distinction, e é de difícil acesso nas livrarias. Publicado por um editor estrangeiro, a edição francesa é cara, especialmente se comparada aos livros de Bourdieu que ganharam o formato de "livro de bolso" (todos os seus livros publicados após 1990), e o estoque é interrompido com frequência.

Se o livro permanece bastante conhecido, ele pode ser considerado, também, um livro que envelheceu. A intenção de "transpor a filosofia do trabalho científico de Gaston Bachelard para o caso das ciências humanas" (BOURDIEU, PASSERON, CHAMBOREDON, 1983, p. 20) não produz mais, sobre as novas gerações de leitores, o mesmo efeito que nos anos 1960. Gaston Bachelard não continua muito presente na filosofia das ciências. Provavelmente, um tema como a "ruptura com o senso comum” não exerça mais a mesma sedução que no contexto politico do pós-68, no qual a "luta contra as ideologias" estava em voga no mundo intelectual, e no qual Louis Althusser, por exemplo, introduzia a expressão “corte epistemológico” para designar a passagem da ideologia à ciência no pensamento de Marx em 1845-1846 (ALTHUSSER, 1965).

Bourdieu, Chamboredon e Passeron não buscaram, provavelmente, escrever um manifesto atemporal. Com frequência, Bourdieu divertia-se com o gênero do manifesto, transformado numa espécie de ritual nos campos artísticos que alcançaram um certo grau de autonomia, e ele considerava, talvez principalmente neste estado de sua carreira, seus livros como publicações provisórias destinadas à revisão e à correção 
(BOURDIEU, DELSAUT, 2002). Ao redigir o Le Métier de sociologue, ele buscava, juntamente com seus coautores, simplesmente registrar um curso ou operar, principalmente para si mesmo, um "retorno reflexivo" sobre seus trabalhos e sobre a epistemologia que ele havia aplicado ${ }^{8}$, algo que lhe era útil neste momento de sua obra. Além disso, a intenção principal do livro parece ligada a um momento específico da história da disciplina. 0 desafio de explicitar os pressupostos do "métier de sociologue" deveria ter uma importância particular em um período em que se instituiu uma licença própria à sociologia (1959), posteriormente um doutorado, e revistas profissionais (Sociologie du Travail, em 1959, Revue Française de Sociologie, em 1960). A reflexão epistemológica do Métier de sociologue é, talvez, especialmente adaptada ao estado de uma disciplina cujas posições dominantes eram, à época, ocupadas por filósofos de formação $0^{9}$. Além disso, o livro é, provavelmente, uma resposta ao Vocabulaire des sciences sociales de Boudon e Lazarsfeld, publicado alguns anos antes.

0 livro está enraizado, portanto, em um contexto, sendo uma tomada de posição em um estado da disciplina, parcialmente transformado na atualidade. Cinquenta anos após a sua publicação, alguns de seus temas ou de suas passagens parecem, talvez, menos transparentes ou mais abstratos. 0 leitor contemporâneo, mesmo na
França, pode não identificar os nomes que os autores do livro, e seus leitores da época, colocavam sob rótulos gerais ("os intuicionistas", "os metodólogos", etc.): Edgar Morin, Paul Lazarsfeld, Lucien Goldman, a Escola de Frankfurt, os estatísticos do INSEE ou, quase totalmente desconhecidos hoje, o reverendo padre Debret ou Joffre Dumazedier. A importância, no livro, da crítica ao "positivismo" (tanto na origem da intenção epistemológica - e não "metodológica" - do livro, quanto de seu plano - "Privilegiamos geralmente a observação. Mas é necessário subordinar a observação à construção, e a construção à ruptura" -), depende também das relações de forca naquele momento. Bourdieu lembra, em 1988, que o livro foi escrito no "topo da invasão 'lazarsfeldiana' na França", o que impunha "reforçar o polo teórico contra o positivismo" (BOURDIEU, CHAMBOREDON, PASSERON, 2005).

Nesta entrevista, realizada vinte anos após a publicação do livro, Bourdieu explica que "de acordo com a época, teríamos que reescrever o Le Métier de sociologue de outro modo" e, se ele considera que "o essencial não foi tão transformado", pensa que, em 1988, seria necessário dar conta da difusão do interacionismo, da etnometodologia e das ideias de Kuhn, assim como o desenvolvimento dos debates históricos. Além disso, acha que seria necessário insistir mais sobre "a ilusão do conhecimento científico" e desenvolver

8. 0 Le Métier de sociologue permite explicitar "uma metodologia que não tinha encontrado sua explicitação" (BOURDIEU, CHAMBOREDON, PASSERON, 1983, p. 18).

9. Em 1960, os membros do comitê editorial da Revue française de sociologie são, por exemplo, em grande proporção, normaliens e/ou agrégés em filosofia (Raymond Boudon, Jean Cazeneuve, Jean Cuisenier, François-André Isambert, Bernard-Pierre Lécuyer, Jean-Daniel Reynaud, Jean Stoetzel). Outros, não sendo normaliens ou titulares de agrégation em filosofia, tinha efetivamente feito estudos filosóficos (René Bassoul, Mattei Dogan, Henri Mendras, Robert Pagès). Somente Edgar Morin e o canadense Jacques Doffny forem deste esquema. 
"a sociologia da sociologia". Retrospectivamente, considera o Le Métier de sociologue "didático", "programático". 0 vê como um "livro de professor [...] que repete incansavelmente que devemos construir, mas sem nunca mostrar, na prática, como se constrói”. Atualmente, ele "diria outras coisas”, e preferiria apresentar exemplos de construção do objeto. No Réponses, publicado em 1992, ele propõe, efetivamente, uma iniciação ao ofício de sociólogo bastante diferente em sua forma, talvez porque Bourdieu mobilize o trabalho de pesquisa e de teorização realizado neste meio tempo. Johan Heilbron assinala que o Le Métier de sociologue corresponde a um momento no qual Bourdieu não está ainda de posse de todas as ferramentas que mobilizará mais tarde. Ele pontua que Bourdieu e sua equipe apoiavam-se muito nos primórdios da "tradição epistemológica francesa", deixando de se inscrever em uma "tradição sociológica precisa”. Além disso, Johan Heilbron menciona que Bourdieu ainda não havia formulado, no momento do Métier de sociologue, sua "teoria da prática”, e que é, ao desenvolver esta última, que ele renuncia a encaminhar, após o volume das "Préalables epistemologiques" atualmente conhecido como Le Métier de sociologue, os dois outros volumes inicialmente previstos (HEILBRON, 2018).

Atualmente, os sociólogos têm interesse em remeter o Le Métier de sociologue ao passado, ou ao menos a sua pretensão em definir a única prática sociológica considerada consequente. É o caso, especialmente, dos partidários da sociologia aplicada. Respondendo às questões que lhe são submetidas por demandantes exteriores à dis- ciplina, principalmente empresas, eles trabalham em condições pouco favoráveis à ruptura com o "senso comum", preconizada no Le Métier de sociologue. 0 pretexto da “mundialização” é utilizado, por exemplo, para dizer que existiriam atualmente "ofícios de sociólogo”, contra a indicação no singular utilizada por Bourdieu, Chamboredon e Passeron no título de seu livro (KAMDEM, IKELLÉ, 2016). Os defensores dessas "sociologias de intervenção" são levados a apresentar a prática sociológica defendida no Le Métier de sociologue como um "posicionamento" entre outros que os sociólogos, igualmente científicos, podem escolher (UHALDE, 2008). Contudo, contra si mesmos, estes pesquisadores tendem a confırmar que a concepção da sociologia veiculada pelo Le Métier de sociologue é atualmente partilhada por muitos sociólogos, e que a referência ao livro é um dos signos de pertencimento à sociologia cientifica - da qual estes sociólogos "de intervenção" não querem ser excluídos.

Nas tentativas para diminuir o crédito do qual se beneficia o Le Métier de sociologue, particularmente com o objetivo de relativizar o imperativo de "instituir uma verdadeira ruptura com o senso comum" (MOREAU, 2014), às vezes mobilizam representantes da sociologia científica que "nuançam" os preceitos do livro de $1968^{10}$. Sociólogos que reivindicam a etnometodologia ou o "pragmatismo", por exemplo, contestam a epistemologia defendida no Le Métier de sociologue. Um dentre eles, que exprime sua simpatia por um "interacionismo realista”, segundo o qual "os indivíduos tem uma visão pertinente do mundo no qual vivem" e são capazes de produzir 
"uma descrição informada das razões" de suas ações, questiona assim o princípio da "não-consciência" apresentado no Le Métier de sociologue (OGIEN, 2010). Se o Le Métier de sociologue é um “clássico", ele não é um "clássico inquestionável”. Um de seus autores, Jean-Claude Passeron, também se distanciou, em um livro publicado em 1991, de alguns aspectos do livro, reinsistindo no caráter histórico das ciências sociais.

“Clássico”, o Le Métier de sociologue é colocado, às vezes, contra o próprio Bourdieu e alguns de seus trabalhos. Em 1995, em uma revista científica bastante conhecida, uma "análise crítica da Miséria do Mundo" atacou o livro afirmando que Bourdieu transgredia ali os preceitos do Métier de sociologue (MAYER, 1995). Nos anos 1990, Bourdieu foi acusado de ter realizado, sem dizer, uma "revolução" em relação às posições que ele defendia inicialmente. Esta invocação do Métier de sociologue, no escopo de uma oposição entre um "jovem" Bourdieu (que reivindicamos) e um "velho" Bourdieu (que colocamos à distância), não é um exemplo isolado: um sociólogo que desempenhou um papel importante na constituição de uma fileira que, a partir dos anos 1990, formou um número considerável de jovens sociólogos recrutados nas instituições parisienses, tende a se colocar como um dos verdadeiros herdeiros do Métier de sociologue. Prestando homenagem a um dos coautores do livro, Jean-Claude Chamboredon, ele considera que Bourdieu e os pesquisadores que trabalhavam em seu centro se "perderiam" ao longo do tempo (WEBER, 2015).

Os elementos que reuni são heteróclitos e parciais. Mesmo assim, eles atestam que, sem ser o livro de Bourdieu mais citado na atualidade, o Le Métier de sociologue não foi esquecido. Mostram que, para frações bastante grandes de sociólogos franceses, ele se trata, atualmente, de uma espécie de "clássico", sendo necessário chamar a atenção ao fato que os "clássicos” estão, também, expostos a leituras superficiais e a formas de neutralização. Contudo, eles dissuadem a tentativa de dizer o que "o livro é”: as teses ou pontos de vista sucessivamente evocados sugerem, sob o risco de fornecer uma impressão de desordem e contradição (mas elas são, talvez, constitutivas da realidade da qual se busca apreender), que a questão de saber "o que é o livro atualmente" permanece como um espaço de lutas, às vezes explícito. No entanto, estes debates são difíceis de separar da questão mais geral de saber o que Bourdieu representa na sociologia francesa contemporânea. Igualmente, parece difícil de isolar o efeito exercido especificamente pelo Le Métier de sociologue: o livro se inscreve em uma obra que, como salientamos, conheceu aprofundamentos e ligeiras inflexões ao longo do tempo, mesmo que ela apresente, igualmente, uma forte coerência.

\section{Sobre o sucesso na França da "revolução simbólica" de Bourdieu}

Sem perder de vista o Le Métier de sociologue, vou evocar agora a questão mais ampla do lugar da sociologia de Pierre Bourdieu na França hoje. Trata-se menos de buscar responder a esta questão, do que ensaiar um modo de formulá-la.

Podemos avançar, sem grande risco de contradição, argumentando que Bourdieu pretendeu transformar a prática sociológica. Um conceito que ele estava tentado a mobilizar para examinar seu empreendimento (BOURDIEU, 2004, p. 104) é aquele de "revolução específica”, utilizado em suas análises sobre a autonomização dos campos 
culturais, particularmente, no caso Manet e do campo artístico (BOURDIEU, 2013). Pascale Casanova apontou nesta direção quando chamou a atenção ao autorretrato que poderia estar contido no curso sobre Manet, proferido entre 1998 e 2000 (CASANOVA, 2013). Falando das críticas violentas que Manet precisou responder, Bourdieu pensava, em parte, nos ataques, então particularmente numerosos, aos quais sua pessoa e sua sociologia estavam submetidos. Transpondo o conceito de "revolução específıca" ao empreendimento do próprio Bourdieu, é necessário atentar que, sem dúvida, essas revoluções não são obra de apenas um indivíduo (ROUEFF, s.d.). No mesmo sentido, Thomas Kuhn sublinhava o caráter eminentemente coletivo - e de longa duração - da "revolução copernicana": Copérnico teria, no máximo, a iniciado (KUHN, 1992). Se Bourdieu inovou na sociologia, ele se apoiou em seus predecessores que - como Freud, Marx, Durkheim, Weber ou Elias tinham iniciado essa "conversão de olhar" sobre as ciências sociais, proposta por ele.

Nessa revolução, o Le Métier de sociologue tem um papel central. De certo modo, o livro (re)funda a sociologia sobre uma epistemologia própria e sobre a aquisição de um habitus específico. Estes adjetivos ("próprio" e "específico") remetem à vontade de autonomização, para mobilizar outra noção que Bourdieu utilizava em suas análises dos campos, e que ele é igualmente tentado a aplicar ao seu próprio empreendimento. No centro do livro, a necessidade de construção do objeto atribui à sociologia um objetivo específico, e a crítica aos grandes "erros" sociológicos denuncia a heteronomia das abordagens concorrentes: em sua propensão a renovar o "senso comum”, o ensaísmo e o positivismo escondem sua subordinação às demandas profanas dos patrocinadores das pesquisas, ou às expectativas de um público mundano; a epistemologia naturalista do positivismo traduziria uma forma de submissão às ciências mais estabelecidas (BOURDIEU, CHAMBOREDON, PASSERON, 1983, p. 18). 0 Le Métier de sociologue participa da construção de uma sociologia "autônoma", em relação às demandas externas e às outras ciências. Durkheim - e Comte antes dele - já ia neste sentido. Bourdieu, contudo, vai mais longe. 0 passo adiante, realizado por ele, será muito visível nos anos 1980: tomando o Estado por objeto, ele fará aparecer a "ciência de estado", heterônoma por definição, que permanece na sociologia de Durkheim. Às vezes, Bourdieu dizia que sua própria contribuição decorria da exigência sistemática de reflexividade: sobre isso, vale lembrar que, em seus trabalhos sobre os campos de produção cultural, ele associa a autonomização ao crescimento da reflexividade. A noção de autonomia se aplica a diversos outros aspectos de seu empreendimento. Bourdieu atribui, por exemplo, à sociologia uma função propriamente científica que não consiste nem a "servir ao poder" (BOURDIEU, 1980), nem "fazer a política por outros meios" (BOURDIEU, 2013). Ele pretende "libertar" a sociologia da dominação da filosofia ou da falta de rigor "acadêmico". 0 último ponto, aliás, não é anedótico: poderíamos comparar as fórmulas utilizadas no Le Métier de sociologue relativamente "à metodologia”, e algumas passagens do curso sobre Manet com relação "à ordem acadêmica” (Ibidem). Nos anos 1990, talvez ainda seja uma autonomização da sociologia frente às expectativas acadêmicas que Bourdieu contribuiria a construir, especialmente ao se liberar do imperativo (acadêmico) da "neutralidade axiológica". Aqueles que lhe 
acusavam, então, de haver "relaxado os preceitos do Métier de sociologue" (MAYER, 1995), não viam (ou não queriam ver) esta continuidade.

Aplicar ao empreendimento de Bourdieu as noções de "revolução específica" e de autonomia, permite melhor formular a questão do "lugar de Bourdieu na sociologia contemporânea": trata-se de se interrogar sobre o grau de sucesso dessa revolução específica, ou sobre o grau ao qual ele elevou a autonomia da sociologia relativamente às diferentes forças suscetíveis a reduzi-la. Podemos indicar diferentes pontos de referência. Sobre o campo literário, Bourdieu evoca o processo de institucionalização: se inicialmente as aspirações à autonomia se apresentam na forma de disposições morais individuais, elas se inscrevem, a partir do sucesso das estratégias de autonomização, em mecanismos objetivos. As análises de Kuhn fornecem informações sobre o caso de uma revolução científica bem sucedida: a "revolução copernicana" demorou, mas em dado momento, tornou-se "difícil de encontrar um grande astrônomo que não fosse copernicano”. Assim, "a crença em um universo geocêntrico", inicialmente "um símbolo de sólido bom senso", transformou-se em "um signo de conservadorismo inflexível", antes de se transmutar em "intolerância excessiva”, e em "completo fanatismo" (KUHN, 1992, p. 304-306). 0 processo parece um pouco diferente nos campos literário e artístico: a revolução da “arte pela arte" na literatura, a revolução impressionista na pintura, ou ainda a "revolução" da "nouvelle vague" no cinema (MARY, 2006), não operaram, mesmo a longo prazo, uma conversão da totalidade dos agentes presentes no campo, mesmo que eles tenham sido, provavelmente, todos afetados de formas e em graus diversos.
Seria errôneo imaginar que todos os sociólogos franceses trabalham, atualmente, como Bourdieu. Ao contrário, o fato de que a organização coletiva criada por ele, através do Centre de Sociologie Européenne, não ter equivalente na atualidade, sugere que nenhum sociólogo trabalha realmente como ele. Poderíamos deduzir que a revolução empreendida por Bourdieu não teve sucesso, ou que a sociologia permanece, na França, em uma posição incerta entre as letras e as ciências? A resposta a esta questão é indiferente, na medida em que uma dimensão do empreendimento de Bourdieu consistia em desenvolver lógicas advindas do campo científico em uma disciplina sociológica nascida, na França, no interior das faculdades de letras. Ao menos até agora, Bourdieu falhou parcialmente neste ponto. 0 jornalismo cultural continua a celebrar "a originalidade" dos sociólogos, como se eles fossem escritores, e as forças internas à disciplina caminham no mesmo sentido.

Com frequência, os perfıs de sociólogos na imprensa são, do início ao fim, contra- perfis de Bourdieu (LEAUTHIER, 1999; AZIMI, 2011), como se o simples fato de se diferenciar dele fosse uma virtude em si. Ao mesmo tempo, se o ponto de referência, para celebrar e apreciar a "originalidade" dos sociólogos, é quase sempre Bourdieu, quer dizer que ele produziu um efeito significativo no campo. De fato, ele é hoje, com certeza e de longe, o sociólogo mais citado na França. Na Revue de Sociologie Française, concorrente da revista que ele fundou, aproximadamente quatro artigos sobre dez, ao longo dos dez últimos anos (2008-2017), se referem ao menos a um de seus textos. Tornou-se muito difícil, mesmo aos sociólogos menos dispostos à sua perspectiva, ignorá-lo. Sua sociologia se difundiu significativamente fora da França, 
e fora do mundo universitário, considerando que seus conceitos passaram a integrar a linguagem dos jornalistas e dos políticos: as expressões de "capital cultural" e de "reprodução social” podem aparecer, sem necessariamente qualquer explicação, em uma entrevista de um membro do governo, ou na de um ex-presidente da república no rádio ${ }^{11}$. 0 autor de um recente panorama da sociologia francesa escreveu que "a corrente crítica inspirada pelo celebre sociólogo é dominante na atualidade”. Mas acrescenta, rapidamente, que "esta abordagem coexiste com outras", e fala em "ecletismo" (FABIANI, 2018). Um artigo publicado algumas semanas antes, em um grande periódico político, assim o definia: "Bourdieu, o homem a debater" ${ }^{2}$; e assinalava que se tratava de "um trabalho entre o alvo e o marco". Sendo o sucesso incontestável, portanto, Bourdieu está sujeito a usos "ecléticos" (que são os limites para a conversão à sua sociologia), permanecendo bastante "debatido", notadamente quando não fosse tomado como "alvo".

No fim de sua vida, o próprio Bourdieu esboçou um balanço em meio-tom:

A revolução que foi realizada, se ela teve sucesso no plano simbólico (ao menos no exterior), na universidade, experimentou um fracasso relativo que se vê bem no destino do grupo: não teria estado continuamente sujeito às pressões e às reações de desconfiança coletiva que visavam impedir sua reprodução 'normal' se, tanto pela lógica de seu funcionamento quanto pelo conteúdo de suas produções cientificas, não tivesse ameaçado as rotinas do campo (BOURDIEU, 2004, p. 107-108).

A alusão ao "destino do grupo" remete às dificuldades que Bourdieu e os membros de seu grupo de pesquisa encontraram no interior da universidade. Bourdieu falou com frequência sobre isso: ele ensinou em instituições prestigiosas, mas marginais no sistema universitário francês, e não dispunha de quase nenhum poder nos espaços nos quais se disputa a atribuição de cargos. É interessante examinar a lista da quarentena de doutorados orientados por Bourdieu. Ela contém doutores que, às vezes, ocupam posições universitárias importantes em países estrangeiros, assim como doutores que foram recrutados, na França, por instituições de pesquisa, ou na universidade para ministrar outras disciplinas, mas somente uma dezena terminou a carreira como professor de sociologia em uma universidade na França, e a metade deles se distanciou de Bourdieu e de sua sociologia, mais ou menos tardiamente, após a defesa da tese. No total, não temos mais que Charles Suaud e Remi Lenoir que foram professores de sociologia em universidades importantes.

As razões as quais podemos sondar para explicar este fenômeno são as mais diversas, mas todas se conectam, sem dúvida, à "desconfiança coletiva” que invocava Bourdieu, e, em última instância, ao conservadorismo da universidade. Na França,

11. "Qual é a principal desigualdade no nosso país ou nos países desenvolvidos? É que alguns não têm fortuna pessoal, nem sequer têm capital cultural, não têm formação que lhes será dispensada durante toda uma parte de sua juventude e estarão, inevitavelmente, em uma posição social que será mais difícil de superar do que outras, ou reprodução social” (François Hollande, ex-presidente da República, "L’invité des matins", France Culture, 18 de abril de 2018).

12. Le Monde, 13 de janeiro, Cahier "Idées", p. 1-3. 
tais dificuldades do grupo frearam a difusão da sociologia de Bourdieu. Mesmo que ele aconselhasse aqueles que trabalhavam no seu entorno a "utilizar, mas citar o mínimo"13 de seus trabalhos, e também a não provocar os adversários, pois estes últimos poderiam desencorajar explicitamente seus estudantes a citar Bourdieu (e a fortiori seus “discípulos”), ou, ao contrário, encorajá-los a citá-lo erroneamente. Anedotas semelhantes circulam ainda hoje, mas as coisas certamente se modificaram um pouco. A morte de Bourdieu e seu reconhecimento crescente no exterior tornam, mesmo na França, sua sociologia cada vez mais difícil de contornar. A renovação geracional também teve um papel: mesmo que seja pouco ensinado em algumas universidades, a sociologia de Bourdieu está muito presente, principalmente a partir dos anos 1990, na imprensa "intelectual” e no mundo editorial: as gerações mais jovens são, em parte, necessariamente formadas a partir desse contato.

Entretanto, não é prudente subestimar a inércia da universidade. A renovação geracional é progressiva e os detentores do poder universitário que, durante a vida de Bourdieu, lhe eram hostis, quando não estão em seus cargos, são substituídos por pessoas mais jovens inclinadas, algumas delas, a reproduzir o mesmo tipo de atitude, principalmente porque foram escolhidas, em parte, com esta finalidade. Uma reserva subsiste nas novas gerações de sociólogos. Diversos trabalhos se apresentam como "superações" de Bourdieu, mesmo que eles o sejam apenas para leitores mais complacentes. Uma estratégia bastante comum consiste, por exemplo, em criticar Bourdieu com a ajuda de contra-argumentos, de fato, provenientes de trabalhos - não citados de Bourdieu (JOLY, 2018). Os empréstimos seletivos à sociologia de Bourdieu, e um ecletismo pouco preocupado com a coerência (o oposto da tentativa do Métier de sociologue em dotar a prática sociológica de fundamentos sólidos e conscientes), são frequentes. Em certo sentido, a postura que progride - e que se distingue claramente da hostilidade geral dos períodos anteriores - é aquela adotada nos anos 1990 por Bernard Lahire, primeiro sociólogo a criar uma posição pretendendo escapar à lógica do "por" e do "contra”, apresentando-se, ao mesmo tempo, como alguém em dívida, e como crítico de Bourdieu (LAHIRE, 1999). A estratégia permite, objetivamente, acumular os lucros científicos associados ao trabalho de Bourdieu, e os lucros sociais distribuídos por um jogo universitário sempre desafiador em relação a ele. De certo modo, ele evoca uma figura da revolução copernicana que Bourdieu adorava citar: Tycho Brahé, que para respeitar “as Escrituras sem sacrificar as principais harmonias matemáticas de Copérnico", reteve as "vantagens matemáticas do sistema de Copérnico, e suprimiu os inconvenientes físicos, cosmológicos e teológicos” (KUHN, p. 275277). No estado atual, os índices do sucesso da "revolução" são, para muitos, ambíguos. Bourdieu é objeto de uma produção bibliográfica abundante que o mantém, quinze anos após seu desaparecimento, no centro do jogo, mas a maior parte dos livros empreendem falsos debates e exibem a integração de sua abordagem. Atualmente, nas especialidades estabelecidas, que antes lhe eram hostis, pesquisadores buscam se apropriar de sua sociologia (podemos pensar no

13. Esta informação é atribuída a Patrick Champagne. 
caso da sociologia do trabalho), o que não é menos ambíguo. Em parte, essa aparente rendição esconde a inércia de uma divisão em especialidades que Bourdieu nunca parou de combater, pois lhe parecia reproduzir mais as divisões sociais do que responder às necessidades científicas.

Gostaria de abordar um último ponto. A história de uma "revolução científica" é aquela do reencontro entre uma ação revolucionária e um espaço. A primeira pretende transformar o segundo, mas sua amplitude e seus efeitos são condicionados pelas dinâmicas específicas deste último. Por esta razão, uma análise da "revolução específica" de Bourdieu - e seus efeitos a médio prazo - deveria se questionar sobre as transformações que, independentemente dele, afetaram a sociologia francesa e que, relativamente aos casos, favorecem ou, ao contrário, dificultam a ação "revolucionária".

Ao longo dos últimos vinte anos, a França, tal como outros países, realizou "reformas" de inspiração neoliberal no ensino superior e na pesquisa. Para serem recrutados e para avançarem na carreira, os pesquisadores são mais incitados a publicar do que no passado. Igualmente, são mais incentivados a "se internacionalizar" - e, de fato, alinhar-se aos critérios dominantes no mundo acadêmico estadunidense -, e a levar em conta mais seriamente as questões consideradas socialmente (economicamente, principalmente) úteis, sobre as quais tendem a se concentrar a atribuição de financiamento. Na França, por enquanto, estas injunções não se impõem todas com a mesma força a todas as disciplinas e a todos os pesquisadores, mas seu efeito global na área não é muito favorável à difusão da sociologia de Bourdieu. As pressões para publicação são acompanhadas, em sociologia, da gene- ralização do gênero de artigo de pesquisa (em detrimento, por exemplo, dos artigos bibliográficos ou puramente teóricos), que era o gênero que Bourdieu e seus colaboradores privilegiavam. Ao mesmo tempo, a estandardização dos artigos, e o curto prazo no qual as pesquisas devem, hoje, ser realizadas, torna difícil a produção de textos comparáveis aos que emanavam do centro de pesquisa de Bourdieu: a construção do objeto que apenas pode ser realizada de modo bastante progressivo, e que supõe, por exemplo, a mobilização de todas as técnicas de pesquisa disponíveis, é muito custosa no quesito tempo. Além disso, as orientações gerais das políticas de pesquisa são muito menos favoráveis à sociologia do que à uma disciplina como a economia que é, desde longa data, mais homogênea em um nível internacional e mais preocupada em produzir conclusões suscetíveis de iluminar os poderes econômicos e políticos. A centralidade do critério da utilidade social encoraja, por sua vez, o retorno à busca de objetos pré-construidos, particularmente os "problemas sociais" que Bourdieu distinguia radicalmente dos "objetos sociológicos" (LENOIR, 1989). 0 alinhamento crescente aos standards estadunidenses suscita o desenvolvimento de práticas estatísticas que se inscrevem fortemente no prolongamento do positivismo dos anos 1950 e 1960, o qual o Le Métier de sociologue tomava como alvo de crítica. Poderíamos, também, interrogarmo-nos sobre a difusão do termo "acadêmico" no vocabulário dos pesquisadores franceses: trata-se de um decalque da palavra inglesa academic e, portanto, não exatamente a palavra que Bourdieu empregava frequentemente com conotação negativa. Cabe perguntar, no entanto, se ela não exprime uma forma de 
conformismo institucional (ou filiação satisfeita à instituição universitária), bastante distante do espírito de Bourdieu?

Seria interessante examinar, ainda, a “autonomização" disciplinar (no sentido que a sociologia das profissões dá a este termo), interna à sociologia. Ao menos sob certos aspectos, a "revolução específica" de Bourdieu ocorreu em um contexto que era favorável ao seu sucesso. Direcionando-se à sociologia no início de sua carreira, Bourdieu escolheria uma disciplina que tinha certamente muito menos prestígio que sua disciplina de formação, a filosofia, mas que começaria a se estruturar. Como aventado acima, a publicação do Métier de sociologue ocorreu em uma época em que o ofício do sociólogo, de fato, se organizava: a sociologia se constituía como disciplina universitária autônoma, novas revistas profissionais surgiam, etc. A refundação da prática sociológica realizada por Bourdieu, acumulando as abordagens da sociologia empírica de origem estadunidense e das tradições teóricas europeias, não foi uma obra, nem mesmo em sua concepção, puramente individual. Em primeiro lugar, ela era partilhada por Raymond Aron, ator central na reconstrução da sociologia francesa nesta época. Uma boa compreensão do empreendimento de Bourdieu (e, notadamente, do livro Le Métier de sociologue) suporia dar conta, ao mesmo tempo, de sua própria originalidade e do grau ao qual ela corresponde às expectativas que lhe preexistem no interior de um espaço sociológico que estava se estruturando.

Tal observação não vale apenas para os anos 1960, e poderíamos dizer que Bourdieu, durante quarenta anos, contribuiu para a definição do "ofício de sociólogo" que se institucionalizava, sob efeito de forças paralelas, ao mesmo tempo convergentes e divergentes em relação ao seu empreendimento. A sociologia, como já salientei, tendia na França, durante esse período, a se homogeneizar ainda mais em torno de um cânone e de formações específicas. Um aspecto importante do sistema de ensino francês - tendo em conta a articulação que existe entre o ensino secundário e a universidade ou, ao menos, as faculdades de letras - é o ingresso da sociologia no ensino secundário geral, e a criação de fileiras de recrutamento de professores. 0 ensino secundário geral francês que, ao nível do liceu, se organizava tradicionalmente em torno das fileiras literárias e científicas se valoriza em 1968, no contexto de forte expansão dos efetivos escolarizados, e de abertura de uma terceira fileira voltada às "ciências econômicas e sociais" e organizada em torno de um ensino marcado por um forte caráter interdisciplinar, com predomínio de formação econômica e sociológica. Concebido principalmente por historiadores e geógrafos que, ligados à École des Annales, estavam engajados na unidade das ciências sociais e, então, reservaram um espaço não negligenciável à história econômica e social nesta formação. Ao menos em sua origem, o espírito desta fileira é muito próximo daquele que caracteriza a École des Hautes Études en Sciences Sociales, instituição que Bourdieu integrou em 1964, e que, antes de se autonomizar em 1975, era uma sessão da EPHE $^{14}$, ligada à École des Annales. Símbolo desta unidade, a sociologia de Bourdieu, particularmente seus trabalhos sobre

14. École pratique des hautes études. 
o sistema escolar ou suas reflexões sobre as classes sociais, integrarão o programa desta fileira dos liceus franceses.

Nos anos 1970, concursos foram realizados para recrutar professores de "ciências econômicas e sociais". Nos anos 1980, a École Normale Supérieure, na tentativa de "modernizar" suas fileiras literárias (LAUTMAN, MERKER, 2017) e de se orientar cada vez mais explicitamente para a formação, não mais de uma "elite" de professores de liceu, mas de pesquisadores para a universidade e as instituições de pesquisa, cria um concurso de entrada compreendendo exames de economia, sociologia e historia social. Igualmente, criou um departamento de ciências sociais, colocado sob a responsabilidade de Jean-Claude Chamboredon, primeiro professor de sociologia recrutado (nos anos que se seguiram a publicação do Métier de sociologue) pela École Normale Supérieure. 0 departamento prepara ao exame de agrégation em ciências sociais, que foi criado em 1976, e em seguida é articulada a criação de um diploma de preparação à tese de doutorado.

Essas transformações afetaram o recrutamento dos pesquisadores em sociologia, ao menos nas instituições mais "prestigiosas”. Por muito tempo, inexistindo a formação específica, os professores de sociologia eram trânsfugas de outras disciplinas. As posições mais elevadas, científica ou universitariamente, eram com frequência ocupadas por normaliens ${ }^{15}$ e/ou filósofos (entre outros exemplos, Raymond Aron, Raymond Boudon, Pierre Bourdieu, Jean-Claude Passeron, eram todos normaliens-filósofos). Este perfil praticamente desapareceu nas novas gerações. Central no recrutamento às disciplinas de história e filosofia, a agrégation em ciências sociais não se tornou uma condição de acesso imprescindível às vagas de sociologia na universidade, mas uma proporção cada vez maior de professores-pesquisadores em sociologia possui este título. Se o recrutamento dos sociólogos permanece diversificado, dois tipos de perfil tornam-se frequentes: uns são ligados à ciência política e aos institutos de estudos políticos, outros ao concurso de ciências sociais da École Normale Supérieure, à agrégation de ciências sociais e, atualmente, à formação doutoral desta instituição.

A institucionalização de uma formação específıca caminha lado a lado à estabilização do cânone de referências e de práticas, e à forma de academização. Esta evolução contribuiu para fazer dos trabalhos de Bourdieu, ou mais exatamente de alguns entre eles, uma "referência escolar" central, embora no interior de um cânone bastante eclético. Se a institucionalização relativa das "ciências econômicas e sociais" contribuiu para a difusão (com uma audiência que excede muito os futuros sociólogos) das análises de Bourdieu sobre o sistema escolar, isso ocorre através de sua inserção ritual no debate com Raymond Boudon, exemplo típico das alternativas escolares (neste caso, a oposição entre o "individualismo" e o "holismo" metodológico) com as quais Bourdieu pretendia romper: isso que as "ciências econômicas e sociais" difundem são, portanto, ao mesmo tempo as análises de Bourdieu e os modos de pensamento contra os quais ele as construiu. Como toda formação "acadêmica", a formação tende a ensinar teses e procedimentos rotinizados, muito mais do que a transmitir o habitus 
do Métier de sociologue. Aliás, este livro é uma referência muito citada, mas sem dúvida não realmente lida nessas formações ligadas ao ensino de ciências econômicas e sociais. A epistemologia dificilmente está presente nesta formação, cuja característica interdisciplinar tomou a história como disciplina matriz, ao invés da filosofia ou da epistemologia. Muito ajustada às propriedades dos sociólogos dominantes dos anos 1960, a reflexão epistemológica do Métier de sociologue está, de certa forma, em forte descompasso com as características dominantes das novas gerações de sociólogos.

\section{Considerações finais}

Minha intervenção oscilou entre a questão anunciada no título e uma interrogação mais ampla sobre o espaço sociológico francês contemporâneo, especialmente em sua relação com Bourdieu. Tal interrogação consiste em compreender o que o espaço sociológico francês contemporâneo deve a Bourdieu. É uma questão reflexiva que a sociologia de Bourdieu, e notadamente o Le Métier de sociologue, impõe a se colocar, me parece. Ora, esta questão é pouco acionada atualmente pelos sociólogos franceses (o trabalho de Gérard Houdeville é uma exceção). Encontramos aqui um outro elemento de resposta à pergunta de partida: Le Métier de sociologue não é o "ar que se respira” na sociologia francesa na atualidade.

Insisti muitas vezes sobre o fato que o lugar da sociologia de Bourdieu permanece um “móvel de lutas” na França, vendo-o como um sinal do fato que a revolução não foi totalmente bem-sucedida, ou então, que ela ainda não “terminou”. Como não é o caso de concluir aqui, gostaria de finalizar com uma citação de Bourdieu que, talvez, reverta o pressuposto:
0 sistema escolar é o lugar da eternização dos clássicos que, a palavra o diz, estão ligados às classes. Mas o sistema escolar, onde a celebração acadêmica dota as obras de uma eternidade um pouco especial, é o inferno dos escritores, e existe uma forma de existência que é mais procurada pelos que lutam neste espaço: ela consiste em existir eternamente como um móvel de lutas no campo Marx, por exemplo, existe como tal (BOURDIEU, 2015, p. 674).

\section{Referências}

ALTHUSSER, L. Pour Marx. Paris: Maspero, 1965. [ALTHUSSER, L. Por Marx. Campinas - SP: Editora da Unicamp, 2015].

AZIMI, R. Raymonde Moulin sociologue. Le journal des arts, n. 339, 21 de Janvier 2011.

BOURDIEU, P. Questions de sociologie. Paris: Éditions de Minuit, 1980. [BOURDIEU, P. Questões de sociologia. Rio de Janeiro: Marco Zero, 1983.

Les Règles de l'art. Paris: Seuil, 1992. [BOURDIEU, P. As regras da arte: gênese e estrutura do campo literário. São Paulo: Companhia das Letras, 1996]

. Réponses: pour une anthropologie réflexive. Paris: Seuil, 1992.

. Esquisse d'une auto-analyse. Paris: Raisons d'agir, 2004. [BOURDIEU, P. Esboço de auto-análise. São Paulo: Companhia das Letras, 2005]

Manet. Une révolution symbolique. Cours au Collège de France 1998-2000, suivis d'un manuscrit inachevé de Pierre et Marie-Claire Bourdieu. Paris: Seuil/Raisons d'agir, 2013.

Sociologie générale. V. 1. Paris: Seuil/Raisons d'agir, 2015.

BOURDIEU, P., CHAMBOREDON, J-C., PASSERON, J-C. Le métier de sociologue. Paris - La Haye: Mouton, 1983. [BOURDIEU, P., CHAMBOREDON, J-C., PASSERON, J-C. Ofício de sociólogo: metodologia da pesquisa na sociologia. Petrópolis - RJ: Vozes, 2004] 
— Le métier de sociologue. Paris - La Haye: Mouton, 2005.

BOURDIEU, P., DELSAUT, Y. L'esprit de la recherche. In: DELSAUT, Y., RIVIĖRE, M-C. Bibliographie des travaux de Pierre Bourdieu, suivi d'un entretien sur l'esprit de la recherche. Pantin: Le Temps des cerises, 2002.

BOURDIEU, P. PASSERON, J-C. Sociology and philosophy in France since 1945: death and resurrection of a philosophy without subject. Social research, v.34, n. 1, 1967.

BOUTET, La pensée critique dans la sociolinguistique en France. Langage et société, n. 160-161, 2017.

CASANOVA, P. Autoportrait en artiste libre ou 'je ne sais pas porquoi je me suis mêlé de ça”. In: BOURDIEU, P. Manet. Une révolution symbolique. Cours au Collège de France 1998-2000, suivis d'un manuscrit inachevé de Pierre et Marie-Claire Bourdieu. Paris: Seuil/Raisons d'agir, 2013, p. 737-741.

FABIANI, J-L. Bourdieu et après? Sciences humaines, n. 301, mars, 2018.

FURETIĖRE, A. Dictionnaire universel. Paris: 1690.

HEILBRON, J. Sociogenèse de la théorie sociologique de Pierre Bourdieu. Zisel, n. 3, 2018, p. 105135.

HOUDEVILLE, G. Le métier de sociologue em France depuis 1945. Renaissence d'une discipline. Rennes: Presses universitaires de Rennes, "Le lien social”, 2007.

JOLY, M. Pour Bourdieu. Paris: CNRS Éditions, 2018.

KAMBEM, E., IKELLÉ, R. Pratiquer la sociologie au Cameroun. Du paradigme du Grand partage à l'emergence de la socio-anthropologie. Sociologies pratiques, n. 32, 2016, p.

KUHN, T. La Révolution copernicienne. Paris: Hachette, 1992.

LAHIRE, B. (dir.). Le travail sociologique de Pierre Bourdieu: dettes et critiques. Paris: La Découverte, 1999.
LAUTMAN, J., MERKER, J. Retour dur la Rue d'Ulm. Commentaires, n. 160, 2017, p. 851-856.

LEAUTHIER, A. Jean-Claude Passeron, l'autre sociologue. Libération, 16 février 1999.

LENOIR, Objet sociologique et problème social. In: CHAMPAGNE, P. et al. Initiation à la pratique sociologique. Paris, Dunod, 1989, p. 53-100. [CHAMPAGNE, P. et al. Iniciação à prática sociológica. Petrópolis - RJ: Vozes, 1998].

MARY, P. La "Nouvelle vague" et le cinéma d'auteur. Paris: Seuil, 2006.

MAYER, N. L'entretien selon Pierre Bourdieu. Analyse critique de La misère du monde. Revue française de sociologie, v. 36, n. 2, 1995, p. 355370.

MERTON, R. K. On the Shoulder of Giants: A Shandean Postscript. Chicago: University of Chicago Press, 1965.

MOREAU, D. B. Sociologie d'intervention: historique et fondements. Revue européenne des sciences sociales, v. 52, n. 2, 2014, p. 191-220.

OGIEN, A. Normativité sociale et normativité neuronale. La découverte des "neorones miroirs" et ses usages en sociologie. Revue française de sociologie, v. 51, n. 4, 2010.

OLLION, É. De la sociologie en Amérique. Éléments pour une sociologie de la sociologie étasunienne contemporaine. Sociologie, v. 2. n. 3, 2011.

PASSERON, J-C. Le Raisonnement sociologique. Paris: Nathan, 1991. [PASSERON, J-C. 0 raciocínio sociológico. Petrópolis - RJ: Vozes, 1996].

PAUGAM, S. (org). A pesquisa sociológica. Rio de Janeiro - Petrópolis: Vozes, 2015.

PERL, P-0. Économie et histoire du monde contemporain. Paris: Armand Colin, "U”, 2013.

PIKETTY, T. BEAUD, S. Eloge des sciences économiques et sociales. Disponivel em: https:// www.alternativeseconomiques.fr/eloge-sciences-economiques-sociales/00003606. 
ROUEFF, 0. La grandeur de Manet. Disponível em: http://www.laviedesidees.fr/La-grandeur-de-Manet.html.

UHALDE, M. L'instrumentalisation de la sociologie en situation d'intervention: analyse critique d'une notion ordinaire. Sociologies pratiques, n. 2008, p. 95-113.

WEBER, F. Préface. In. CHAMBOREDON, J-C. Jeunesse et classes sociales. Paris: Éditions Rue d'Ulm/Presses de l'École normale supérieure, 2015, p. 5-15.

Recebida em: 17/05/2018

Aprovada em: 20/12/2019 